\title{
Post-midnight onset of spread-F at Kodaikanal during the June solstice of solar minimum
}

\author{
J. Hanumath Sastri \\ Indian Institute of Astrophysics, Bangalore 560 034, India, e-mail: jhs@iiap.ernet.in
}

Received: 25 January 1999 / Revised: 26 March 1999 / Accepted: 30 March 1999

\begin{abstract}
At dip equatorial stations in the Indian zone, spread-F conditions are known to develop preferentially around midnight during the June solstice (northern summer) months of low solar activity, in association with a distinct increase in $\mathrm{F}$ layer height. It is currently held that this onset of spread-F far away from the sunset terminator is due to the generalised Rayleigh-Taylor instability mechanism, with the gravitational and crossfield instability factors (and hence $F$ layer height) playing important roles. We have studied the quarterhourly ionograms of Kodaikanal $\left(10.2^{\circ} \mathrm{N} ; 77.5^{\circ} \mathrm{E}\right.$; dip $4^{\circ} \mathrm{N}$ ) for the northern summer months (May-August) of 1994 and 1995 to ascertain the ambient ionospheric conditions against which the post-midnight onset of spread-F takes place. A data sample of 38 nights with midnight onset of spread-F and 34 nights without spread-F is used for the purpose. It is found that a conspicious increase in $\mathrm{F}$ layer height beginning around 2100 LT occurs on nights with spread-F as well as without spread-F. This feature is seen in the nocturnal pattern of $F$ layer height on many individual nights as well as of average $\mathrm{F}$ layer height for the two categories of nights. The result strongly suggests that the F layer height does not play a pivotal role in the midnight onset of spread-F during the June solstice of solar minimum. The implications of this finding are discussed.
\end{abstract}

Key words. Ionosphere (equatorial ionosphere; ionospheric irregularities)

\section{Introduction}

Equatorial spread-F (ESF) refers to the destabilised state of $\mathrm{F}$ region plasma in the dip equatorial region with field-aligned irregularities spanning seven orders of magnitude in size $(0.1 \mathrm{~m}-500 \mathrm{~km})$ and fourteen orders of magnitude in strength (Kelley, 1985). ESF as seen on bottomside ionograms with which we are primarily concerned here are due to intermediate-scale irregularities (100 $\mathrm{m}$ to a few $\mathrm{km}$ in size; Booker et al., 1986). It is now accepted that the generalised collisional RayleighTaylor (RT) plasma instability is the primary mechanism responsible for the generation of intermediate-scale ESF irregularities or ionogram spread-F (e.g. Kelley et al., 1981).

There is an extensive body of literature on the morphology of ionogram ESF documenting such aspects as the solar cycle, seasonal and geomagnetic activity-related variations at specific locations round the globe and the longitudinal differences in them (e.g., Clemesha and Wright, 1966 and references therein; Skinner and Kelleher, 1971; Chandra and Rastogi, 1972; Sastri and Murthy, 1975; Sastri et al., 1979a, b; Abdu et al., 1981, 1992). A distinctive feature of the incidence of spread-F conditions in the Indian equatorial zone is the solar activity-dependent seasonal behaviour. During high solar-activity epochs, the occurrence of spread-F peaks in the post-sunset period (around 2000 LT) and this post-sunset peak is higher during equinoxes and lower during solstices, particularly the June solstice. The ubiquitous post-sunset peak is also seen in low solaractivity epochs but only in equinoxes. During the June solstice (local summer) and to a lesser extent in the December solstice (local winter), the peak occurrence of spread-F is seen in the post-midnight hours (around $0300 \mathrm{LT}$ ) preceded by an abnormal increase of $\mathrm{F}$ region height (Chandra and Rastogi, 1972; Sastri et al., 1979a; Subbarao and Krishnamurthy, 1994). A pre-sunrise (secondary) maximum of spread-F occurrence is also evidenced in the Brazil sector at solar minimum, particularly during the December solstice (MacDougall et al., 1998). The work of Subbarao and Krishnamurthy (1994) suggests that the shift in peak occurrence of spread-F from post-sunset to post-midnight hours at solar minimum can be accounted for, in general, in terms of the generalised Rayleigh-Taylor (R-T) instability mechanism. Estimates of the linear instability 
growth rates show that the increase in $\mathrm{F}$ region height that precedes the post-midnight onset of spread-F can render the $\mathrm{F}$ region unstable to the combined effects of cross-field and gravitational terms of generalised RT instability. It is, however, not yet known whether the increase in $\mathrm{F}$ region height is a sufficient condition for the post-midnight onset of ionogram spread-F. In this paper we address this question. Our study shows that the the increase in $\mathrm{F}$ region height and the consequent elevated $\mathrm{F}$ layer is not a sufficient condition for the postmidnight onset of spread-F (mostly frequency type) during the June solstice of solar minimum. We present and discuss this primary finding in the following sections.

\section{Results}

The present study is based on quarter-hourly ionograms acquired with a IPS-42 ionosonde at Kodaikanal $\left(10.2^{\circ} \mathrm{N} ; 77.5^{\circ} \mathrm{E}, \operatorname{dip} 4^{\circ} \mathrm{N}\right)$ during the June solstice months (May-August) of 1994 and 1995. The monthly mean of solar decimetric $(10.7 \mathrm{~cm})$ flux varied in the range 75.7-83.2 units during the months under consideration, testifying to the low solar activity conditions then. Careful scrutiny of our ionogram database showed that post-midnight onset of spread-F conditions preceded by a conspicuous increase in $\mathrm{F}$ layer height is a fairly common feature. The spread-F is mostly of frequency type as also reported earlier by Subbarao and Krishnamurthy (1994). This behaviour which is expected from earlier studies can be seen from Fig. 1 wherein the local time variation of height of bottomside $F$ region, $h{ }^{\prime} F$ is shown for three such nights. It is evident that on spread-F nights, the increase in $h{ }^{\prime} F$ typically starts after $2100 \mathrm{LT}$ and $\mathrm{h}$ ' $\mathrm{F}$ reaches a maximum value of $300 \mathrm{~km}$ or higher at or just after midnight. The onset of spread-F conditions is seen when the layer is ascending (10 May and 17 July) or when it is descending (29 July). We, nevertheless, also found that a mere increase of $\mathrm{h}$ ' $\mathrm{F}$ to $300 \mathrm{~km}$ or more does not necessarily lead to spread-F conditions. This behaviour can be seen from $h^{\prime} F$ variations on three representative nights also graphed in Fig. 1 (curves with solid circles). The maximum value of $h^{\prime} F$ in fact was $325 \mathrm{~km}$ and higher on two of these nights but spread-F conditions were not seen.

We have also carried out a statistical analysis to verify that the absence of any significant difference in the behaviour of $h$ ' $F$ on nights with and without spread-F is not confined to a few individual nights but is a regular feature so as to manifest in the gross behaviour of $h^{\prime} F$. For this purpose we have divided the database into nights with and without post-midnight onset of spread$\mathrm{F}$, and computed the average $\mathrm{h}$ ' $\mathrm{F}$ values for the two categories of nights. There are 38 nights with spread-F and 34 nights without spread-F and Fig. 2 shows the local time variation of average values of $h^{\prime} F$ for the two types of nights (middle panel). It is to be noted that for no-spread-F nights, $h$ ' $F$ values are not available after 0200 LT due to no-echo condition and hence are not

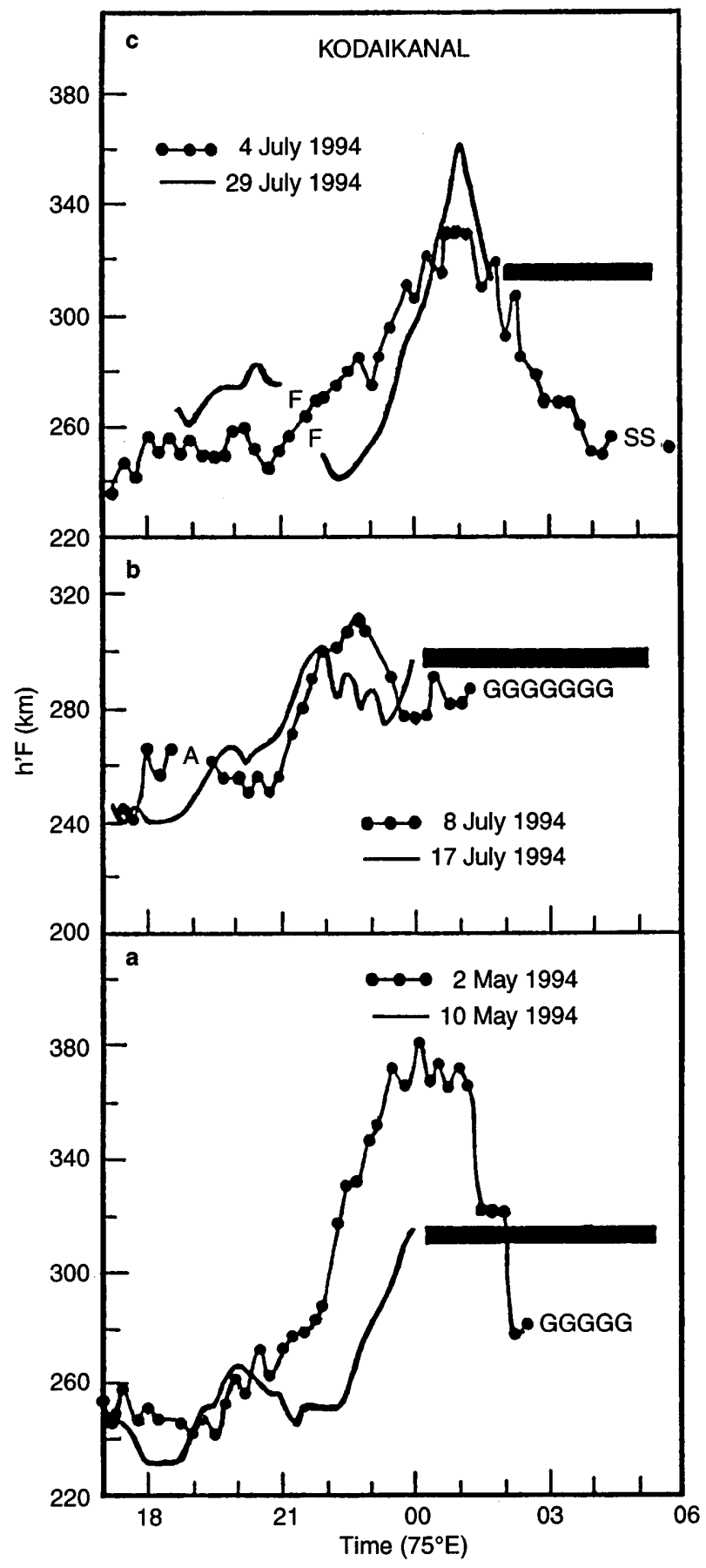

Fig. 1. Examples of the local time variation of $h^{\prime} \mathrm{F}$ at Kodaikanal on nights with post-midnight onset of spread-F (solid curves) and without spread-F (curves with filled circles). The solid rectangles represent the duration of spread-F. The qualifying letters $G$ and $S$ indicate no-echo and interference conditions respectively

shown.It is quite clear from Fig. 2 that there is no significant difference either in the pattern of variation of $h^{\prime} F$ or the absolute midnight maximum value of $h^{\prime} F$ for the two sets of nights. The increase in $\mathrm{h}^{\prime} \mathrm{F}$ begins after $2100 \mathrm{LT}$ and attains a maximum value of about $300 \mathrm{~km}$ around midnight irrespective of whether spreadF conditions follow or not. Our analysis thus highlights that an increase of the height of bottomside $\mathrm{F}$ region 


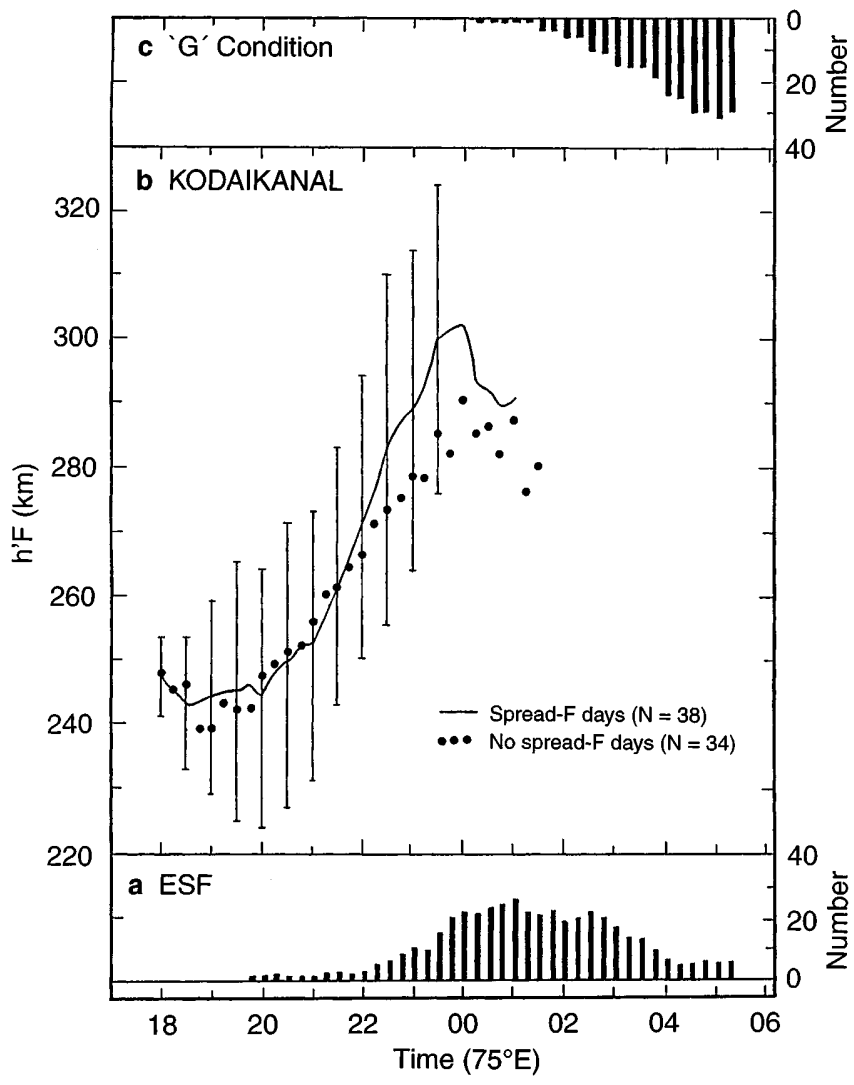

Fig. 2. Local time variation of average $h^{\prime} F$ on nights with and without spread-F in post-midnight hours. The vertical bars represent standard deviations of the average values for spread-F nights. Also shown are the local time variation of spread-F occurrence and $G$ (no echo) condition for the set of spread-F nights

(indicative of a reversal of vertical plasma drift from its downward direction till then to upward) and the consequent presence of an elevated $\mathrm{F}$ region (around $300 \mathrm{~km}$ ) are not crucial for the post-midnight generation of intermediate scale ESF irregularities at Kodaikanal during the June solstice of solar minimum years.

Also shown in Fig. 2 are the local time dependence of spread-F conditions (bottom panel) and no-echo condition (upper panel) for the set of spread-F nights. This is done because no-echo conditions will frequently be seen on equatorial ionograms in the pre-sunrise period at solar minimum. This however has no bearing on the assessment of spread-F conditions in the post-midnight period in our data sample, as can clearly be seen from Fig. 2. The no-echo condition is prominently seen in the interval 0300-0515 LT whereas the preferred interval for spread-F conditions is 2330-0300 LT (see also Fig. 1). The equatorial $\mathrm{F}$ layer vertical drift and hence layer height are known to be sensitive to geomagnetic activity, particularly during the nighttime period (see, Fejer, 1997 and references therein). We have verified for the sake of completeness, that there is no significant change either in the distribution of the daily $\mathrm{A}_{p}$ index or its mean value between nights with and without postmidnight spreadF, as can be seen from Fig. 3. Our data sample mostly pertains to quiet geomagnetic conditions $\left(\mathrm{A}_{p}<15\right)$.

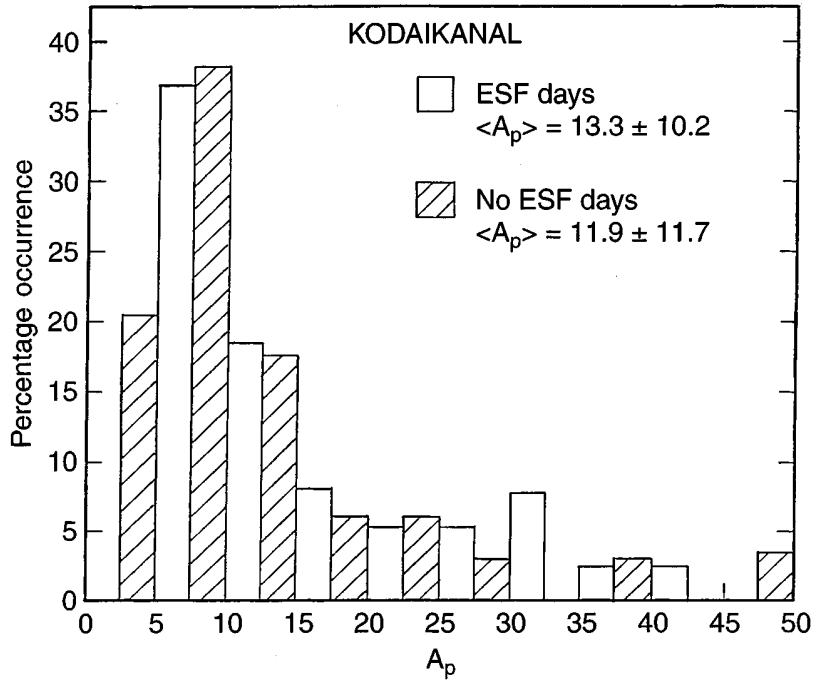

Fig. 3. Distribution of the daily values of geomagnetic $A_{p}$ index for nights with and without post-midnight onset of spread-F at Kodaikanal. Mean levels of the index are also given for the two sets of nights

\section{Discussion}

The post-midnight onset of spread-F preceded by an increase in $\mathrm{F}$ layer height can, in general, be understood in terms of generalised collisional R-T instability, as demonstrated earlier by Subbarao and Krishnamurthy (1994). Their work shows that the local time variation of the RT growth rate due to combined effects of the gravitational and cross-field instability terms closely follows that of the layer height and can be as high as $0.4510^{-2}\left(\mathrm{~s}^{-1}\right)$ when $\mathrm{h}^{\prime} \mathrm{F}$ is around $300 \mathrm{~km}$ (see Figs. 2 and 4 of their paper). The present study however brings to light the fact that an elevated bottomside $F$ region (around $300 \mathrm{~km}$ ) does not always lead to spread-F conditions in the post-midnight period on equatorial ionograms. Several possibilities exist that can account for this behaviour.

First, although the $\mathrm{F}$ region height conditions are favourable for the growth of RT instability, other factors that inhibit the instability growth may be operative on individual nights. Earlier studies showed that besides the $\mathrm{F}$ region height, thermospheric meridional neutral winds and vertical winds do control the RT growth rate (e.g. Sekar and Raghava Rao, 1987; Maruyama, 1988; Mendillo et al., 1992). Downward (upward) vertical winds aid (inhibit) the RT instability growth rate and meridional winds, irrespective of direction, always inhibit the RT instability process. Now it is well known that the thermospheric neutral wind field at equatorial latitudes is determined not only by the global circulation due to solar forcing but also by the semi-permanent equatorial midnight temperature maximum, MTM (Herrero et al., 1993 and references therein; Sastri et al., 1994; Goembel and Herrero, 1995; Colerico et al., 1996). MTM is strongest in summer and its characteristics (amplitude and time of maximum) are highly variable from one day to 
another. So much so, it is possible that the day-to-day variability of the neutral wind field (due to MTM and other factors like ion drag) could induce corresponding variability in development of spread-F conditions in the post-midnight hours. Alternatively, even if the bottomside $\mathrm{F}$ region is high, seed perturbations in plasma density (in the zonal direction) may be absent to aid the growth of RT instability. These possibilities merit rigorous assessment through systematic and coordinated measurements with ionosondes and optical instrumentation (Fabry-Perot interferometer) at equatorial locations.

Second, the post-midnight onset of spread-F may not be due entirely to destabilisation of local plasma but to the overhead passage of irregularities patches that formed elsewhere (east or west of the station). We believe that that this is most likely cause for the absence of a one-to-one relationship between the elevated $F$ region and post-midnight onset of spread- $F$ reported here. Observations made with Advanced Ionospheric Sounders (AIS) with directional and Doppler capabilities lend some support to this view. Argo and Kelley (1986) presented one event for the CONDOR project interval to show that the postmidnight onset of spread-F at the dip equatorial station, Huancayo, Peru is indeed due to the overhead passage of an irregularities patch (tentatively identified as a detached or fossil plume) from west to east with an average speed of $60 \mathrm{~ms}^{-1}$ (see Fig. 5 of their paper). The most recent observations of MacDougall et al. (1998) with the Canadian Advanced Digital Ionosonde (CADI) at Fortaleza, Brazil also show the relevance of eastward convecting patches of irregularities (speed $50 \mathrm{~ms}^{-1}$ ) to postmidnight spread-F. Their work however suggests a contribution of other physical processes as well. The convecting patches are found to be collocated with bulges on the bottomside $\mathrm{F}$ region caused by a downward vertical velocity perturbation. The bulges are considered as insignia of R-T instability and it is shown that the gradient-drift instability (with the gradient and the drift in the horizontal direction) can act on the bulges to produce the spread-F irregularities. The association of post-midnight spread-F conditions with an elevated $F$ region that is seen in earlier studies as well as here for dip equatorial stations in the Indian sector during the June solstice at solar minimum therefore merits further investigation. It is pertinent to mention in this context that the AIS observations at Huancayo, Peru indicate the absence of a significant change in local $\mathrm{F}$ region height with the postmidnight onset of spread-F (Argo and Kelley, 1986). These measurements correspond to the equinox season on the declining phase of solar cycle, and it is not known whether the same behaviour is obtained in the June solstice at solar minimum of interest here. The measurements of MacDougall et al. (1998) on the other hand, cover an entire annual cycle at solar minimum. Apparent differences thus seem to exist at different longitudes in the relationship between convecting patches of irregularities, changes in local $F$ layer height and post-midnight onset of spread-F. Simultaneous observations of the equatorial ionosphere-thermosphere system at different longitudes will help unravel the origin of these differences and gain a better understanding of the conspicuous post-midnight onset of spread-F conditions on equatorial ionograms at solar minimum.

Acknowledgement. Topical Editor D. Alcaydé thanks M. A. Abdu for his help in evaluating this paper.

\section{References}

Abdu, M. A., J. A. Bittencourt, and I. S. Batista, Magnetic declination control of the equatorial $\mathrm{F}$ region dynamo electric field development and spread F, J. Geophys. Res., 86, 1144311446, 1981.

Abdu, M. A., I. S. Batista, and J. H. A. Sobral, A new aspect of magnetic declination control of equatorial spread-F and $\mathrm{F}$ region dynamo, J. Geophys. Res., 97, 14,897-14,904, 1992.

Argo, P. E., and M. C. Kelley, Digital ionosonde observations during equatorial spread-F, J. Geophys. Res., 91, 5539-5555, 1986.

Booker, H. G., P. K. Pasricha, and W. J. Powers, Use of scintillation theory to explain frequency spread on $\mathrm{F}$ region ionograms., J. Atmos. Terr. Phys., 48, 327-354, 1986.

Chandra, H., and R. G. Rastogi, Equatoriasl spread-F over a solar cycle, Ann. Geophys., 28, 37-44, 1972.

Clemesha, B. R., and R. W. H. Wright, Survey of equatorial spread$\mathrm{F}$, in Spread-F and its Effects Upon Radio Wave Propagation and Communication, ed. P. Newman, Technivision, Maidenhead, England, 3-27, 1966.

Colerico, M., M. Mendillo, D. Nottingham, J. Baumgardner, J. Meriwether, J. Mirick, B. W. Reinisch, J. L. Scalli, C. G. Fesen, and M. A. Biondi, Coordinated measurements of $\mathrm{F}$ region dynamics related to the thermospheric midnight temperature maximum, J. Geophys. Res., 101, 26,783-26,793, 1996.

Fejer, B. G., The elctrodynamics of the low-latitude ionosphere: recent results and future challenges, J. Atmos. Sol. Terr. Phys., 59, 1465-1482, 1997.

Goembel, L., F. A. Herrero, Anomalous meridional thermospheric neutral winds in AE-E NATE data: Effects of the equatorial nighttime pressure bulge, Geophys. Res. Lett., 22, 271-274, 1995.

Herrero, F. A., N. W. Spencer, and H. G. Mayr, Thermospheric and $\mathrm{F}$ region plasma dynamics in the equatorial region, $A d v$. Space Res., 13, 201-220, 1993.

Kelley, M. C., Equatorial spread-F: recent results and outstanding problems, J. Atmos. Terr. Phys., 47, 745-752, 1985.

Kelley, M. C., M. F. Larsen, C. La Hoz, and J. P. McClure, Gravity wave initiation of equatorial spread-F, J. Geophys. Res., 86, 9087-9100, 1981.

MacDougall, J. W., M. A. Abdu, P. T. Jayachandran, J. -F. Cecile, and I. S. Batista, Presunrise spread-F at Fortaleza, J. Geophys. Res., 103, 23,415-23,425, 1998.

Maruyama, T., A diagnostic model for equatorial spread-F 1. Model description and application to electric field and neutral wind effects, J. Geophys. Res., 93, 14,611-14,622, 1988.

Mendillo, M., J. Baumgardner, X. Pi, P. J. Sultan, and R. Tsunoda, Onset conditions of equatorial spread-F, J. Geophys. Res., 97, 13,865-13,876, 1992.

Sastri, J. H., and B. S. Murthy, Spread-F at Kodaikanal, Ann. Geophys., bf 31, 409-414, 1975.

Sastri, J. H., B. S. Murthy, and K. Sasidharan, Range and frequency spread-F at Kodaikanal, Ann. Geophys., bf 35, 153158, 1979a.

Sastri, J. H., K. Sasidharan, V. Subrahmanyam, and M. Sriramarao, Seasonal and solar cycle effects in the occurrence of equatorial spread-F configurations, Ind. J. Radio Space. Phys., bf 8, 135-138, 1979b. 
Sastri, J. H., H. N. R. Rao, V. V. Somayajulu, and H. Chandra, Thermospheric winds associated with equatorial midnight temperature maximum, Geophys. Res. Lett., 21, 825-828, 1994.

Sekar, R., and R. Raghava Rao, Role of vertical winds in the Rayleigh-Taylor mode instabilities of the night-time equatorial ionosphere, J. Atmos. Terr. Phys., 49, 981-985, 1987.
Skinner, N. J., and R. F. Kelleher, Studies of F region irregularities at Nairobi-1, from spread-F on ionograms 1964-70, Ann. Geophys., 27, 181-194, 1971.

Subbarao, K. S. V., and B. V. Krishnamurthy, Seasonal variations of equatorial spread-F, Ann. Geophys., 12, 33-39, 1994. 